\title{
Restudy on Macro Logistics Cost of China
}

\author{
Xingang Weng ${ }^{1}$, Xufeng $\mathrm{Du}^{2}$ \\ ${ }^{1}$ Beijing Wuzi University, Beijing, China \\ ${ }^{2}$ Department of Postgraduate, Beijing Wuzi University, Beijing, China \\ Email:315505728@qq.com
}

Received 28 September 2015; accepted 10 November 2015; published 13 November 2015

Copyright (C) 2015 by authors and Scientific Research Publishing Inc.

This work is licensed under the Creative Commons Attribution International License (CC BY). http://creativecommons.org/licenses/by/4.0/

(c) $\underset{\mathrm{EY}}{\mathrm{BY}}$ Open Access

\begin{abstract}
Some views about macro logistics cost of China related literature and business recent years were re-analyzed. There are still some questionable points about the total cost of social logistics nowadays. It is pointed out that we should re-examine and research the way of view of macro logistics cost on the basis of the actual data and stimulated data.
\end{abstract}

\section{Keywords}

Social Logistics Cost, Industrial Structure, Simulated Data

\section{Introduction}

In the 1990s, the growth rate of global commercial transactions is 3 times faster than the world growth rate at least, so that logistics has become one of the largest shares of international business activities. Based on this case, the cost of logistics and related indicators become the most important indicator of the performance of the logistics operation. Only in 2013, the total logistics of our country had reached 197.8 trillion. It has become an important industry emerging. However, many basic views and opinions about social logistics costs are still very different. For example, logistics companies hold that the social logistics costs between countries based on the proportion of GDP and social reasons may not be used to tell the situation of Chinese logistics operations. For the gap between China and foreign countries accounted for the proportion of GDP attributed to the formation of inefficient logistics enterprises or enterprise logistics activities according to the development of industry policy. On the other hand, we have a representative point of view from the industry associations that reducing the logistics costs means increasing profits on the contrary. At least, reducing the cost of logistics is worth the effort. It seems that the lower logistics costs, the more the savings are. The above situation shows that we are still being trapped in the blind area and that so much misunderstanding about the macro logistics cost of China still exists. It is necessary to restudy the questions and relevant clarification is urgently needed in China nowadays (newly increased). 


\section{The Defect of Indicators and Chaos in the Reading}

For now, the macroscopically logistics statistical indicators (social logistics total cost/GDP) used very-frequently at home and abroad, it emphasizes practical significance of the logistics cost of the input and output, that is social logistics costs of the collection in a period: the logistics cost of a unit of GDP requires belongs to the category of logistics cost. If the logistics service output expression of the whole society as $G=C+V+M$, name $C$ the value of logistics activities in the consumption of production materials, $V$ the value of logistics practitioners create with their labor, $M$ the value of logistics professionals create for the society, the social total cost of logistics is the $C+V$, The value of logistics resources consumed in a unit of output that the enterprise create can be expressed as $(C+V) /(C+V+M)$. The realistic meaning of the expression is just as like (social logistics total cost/GDP), while the latter expression has some obviously unreasonable issues. Because a period of GDP in one country or region will not all directly consume logistics resources, such as banking, insurance, software development, etc. Although these activities will indirectly need logistics services, these have been reflected in other industries, these irrelevant parts in the indicators that simply reflect the input and output of the logistics activities, can produce double counting, especially using relative expression will inevitably cover-up the truth. Now we will further analysis the index of (social logistics total cost/GDP):

First, we use MALC (Macro logistics cost) on behalf of the social total cost of logistics that is all various cost the national economy used in social logistics. According to the high and low value-added and rely on logistics activities (or any direct relationship), all products (including services) of a country or region in a certain period are divided into four categories: high value-added products, low value-added products, products have direct contact with the logistics activities and products have no direct contact with the logistics activities. High valueadded products output value in $H_{1}$, low value-added products output in $L_{1}$; products have direct contact with the logistics activities in $\mathrm{H}_{2}$, and products have no direct contact with the logistics activities in $L_{2}$; then all products can be divided into four categories: high value-added logistics demand products $H_{1} H_{2}$, logistics demand of higher value added products $H_{1} L_{2}$ high degree of logistics demand, low added value products $L_{1} H_{2} L_{1} L_{2}$ and low value-added logistics demand products.

$$
\text { GDP of one country or area in a certain period }=H_{1} H_{2}+L_{1} H_{2}+H_{1} L_{2}+L_{1} L_{2}
$$

On the basis of (1)

$$
\text { MALC/GDP }=\operatorname{MALC} /\left(H_{1} H_{2}+L_{1} H_{2}+H_{1} L_{2}+L_{1} L_{2}\right)
$$

According to the previously mentioned, it was contrary to the imputation principle of cost that join the value created by those non logistics activities into the denominator of a formula for measuring the input output of logistics activities. As a result, remove the value of the product which is not directly demand for logistics activities or is very low demand $\left(H_{1} L_{2}+L_{1} L_{2}\right)$ from the denominator to format Formula (3)

$$
\operatorname{MALC} /\left(H_{1} H_{2}+L_{1} H_{2}\right)
$$

MALC/GDP into MALC/ $\left(H_{1} H_{2}+L_{1} H_{2}\right)$, which more accurately apply the principle of the account of the cost, more objectively reflect the logistics resources matching concept, said logistics resources needed consumption per unit of output; On the numerical, molecular unchanged, the denominator decreases, so the ratio will rise correspondingly. But according to the national conditions, it increases in the different size. According to the models and assumptions, we might make the following corollary: for the country with large output and direct demand for logistics activity (the country without direct demand for logistics activity has small output ), the size of its rise will be small after rejecting $\left(H_{1} L_{2}+L_{1} L_{2}\right)$; on the contrary, it will be large. Investigation of the United States, we found that the proportion of the first and second industry combined of The United States was $46.04 \%$, while the share down to $21.2 \%$ by 2011; And the sum of the first, second industry accounts of our country was $76.1 \%$ of GDP in 1978, while presents a decreasing trend, but still more than half until 2013, to 53.9\%. Because $\left(H_{1} L_{2}+L_{1} L_{2}\right)$ has no direct relation with the logistics activities of industrial output, such as information transmission, computer services, software industry, the financial industry, scientific research, technical services and geological exploration, education, health, social security, social welfare, cultural, sports, entertainment, and news publishing industry, etc. Based on "with the first-Clark theorem" (Petty-Clark's law) of three times industry evolution and the consideration of the reality, the third industry, especially modern service industry is relatively developed in the United States, but our country is in the later period of industrialization development, ter- 
tiary industry output value although growth was $46.1 \%$ in 2013 , but the traditional service industries such as transportation, warehousing and postal service, wholesale and retail industry for logistics have just need to account for more than $30 \%$ of the third industry. We can conclude that: the reduce part of denominator for Formula (2) $\left(H_{1} L_{2}+L_{1} L_{2}\right)$ in the United States is far greater than the parts of our country, because the molecules remains the same, the size of the ratio of the overall elevated also should be greater than the rise of our country, the final Formula (3) reflects the real value probably reached the level of our country, even higher than the year of the corresponding level.

Now according to the way that the Formula (2) changed into the Formula (3), to recalculate the actual data of China and the United States (Table 1):

The actual data in Table 2 confirmed the inference of the model: The actual values were corresponding rise in China and the United States after getting rid of the part that have no direct relations with the logistics activity from the Formula (2). But as a result of the different industrial structure of China and the United States, there was big difference in the size of increase. Due to the relatively large material production department of our country, especially the industrial created almost half of GDP, combined with its rigid demand for logistics industry. The raising of the data was less than the United States in Formula (2) after the adjustment of amplitude. In order to more clearly to see this change, the following will compare the corresponding data of 1998-2011 (Figure 1 and Figure 2).

Before the adjustment, our country social logistics cost of GDP were higher than in the United States, at least 7.2\% higher, up to 9.9\% (as shown in Figure 1); got rid of the value that has nothing to do with the logistics activities, we found that in addition to the year 2003 (24.5\%), 2009 (24.8\%), this two years the proportion of the two countries is equal, the rest of the year the United States are higher than the ratio in our country, and in 2006, 2007, 2008, the ratio in the United States is over the corresponding year in our country, this dramatic differences probably originated in 2007, the financial crisis on the horizon (as shown in Figure 2).

The above process only got rid of the value that has nothing to do with the logistics activities legitimately on the basis of the original general, the numerical had produced a sharp reversal. Hence it can be seen the inherent defects of the original index (MALC/GDP): Not only could not objectively reflect the operation of the logistics industry but also was easy to come to the conclusion that against the facts compared with western developed

Table 1. Contrast before and after the adjustment of China [1] [2].

\begin{tabular}{lcc}
\hline Year & MALC/GDP of China (\%) & MALC/ $\left(H_{1} H_{2}+L_{1} H_{2}\right)$ of China (\%) \\
\hline 1998 & 19.8 & 24.9 \\
1999 & 19.6 & 24.9 \\
2000 & 19.2 & 24.7 \\
2001 & 18.5 & 24.2 \\
2002 & 18.3 & 24.3 \\
2003 & 18.4 & 24.5 \\
2004 & 18.2 & 24.1 \\
2005 & 18.3 & 24.4 \\
2006 & 17.8 & 23.8 \\
2007 & 17.1 & 23.2 \\
2008 & 17.4 & 23.5 \\
2009 & 17.8 & 24.8 \\
2010 & 17.7 & 24.4 \\
2011 & 17.8 & 24.5 \\
\hline
\end{tabular}

Caption: "output is directly related to logistics activity” in the graph calculation actually contains transportation industry which has no direct relations with the logistics activities, based on availability, the data still includes transportation, so the final calculation value is slightly less than the actual value. 
25

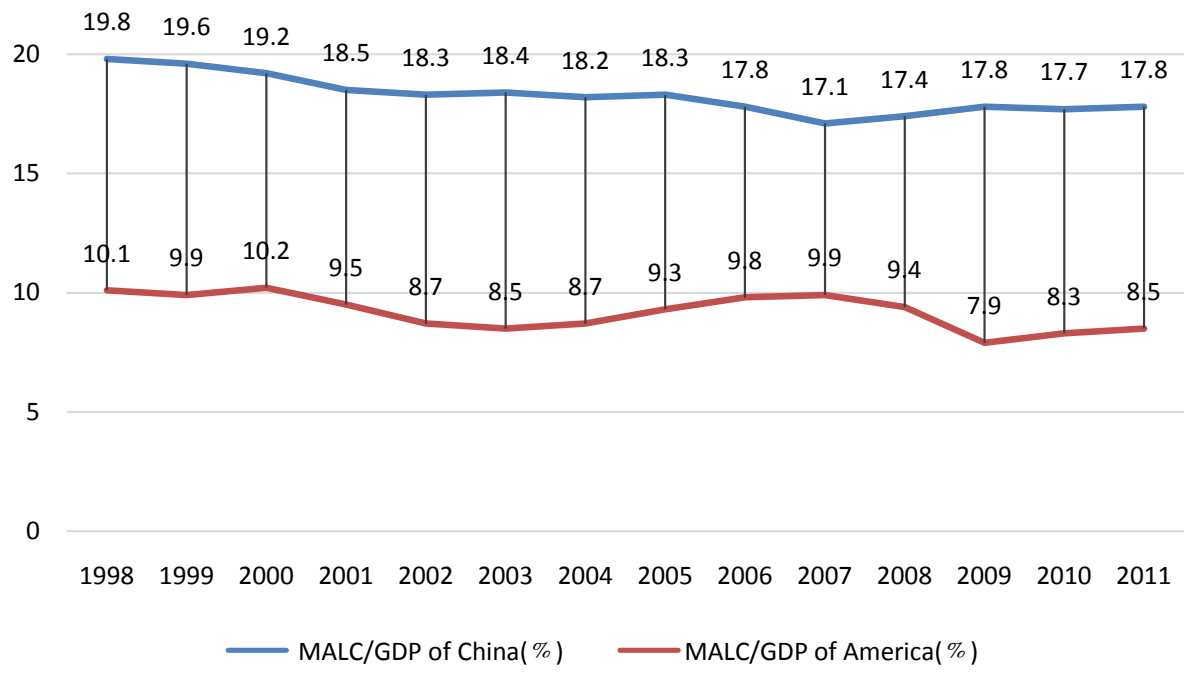

Figure 1. MALC of China and America (1983-2010) [2]-[5].

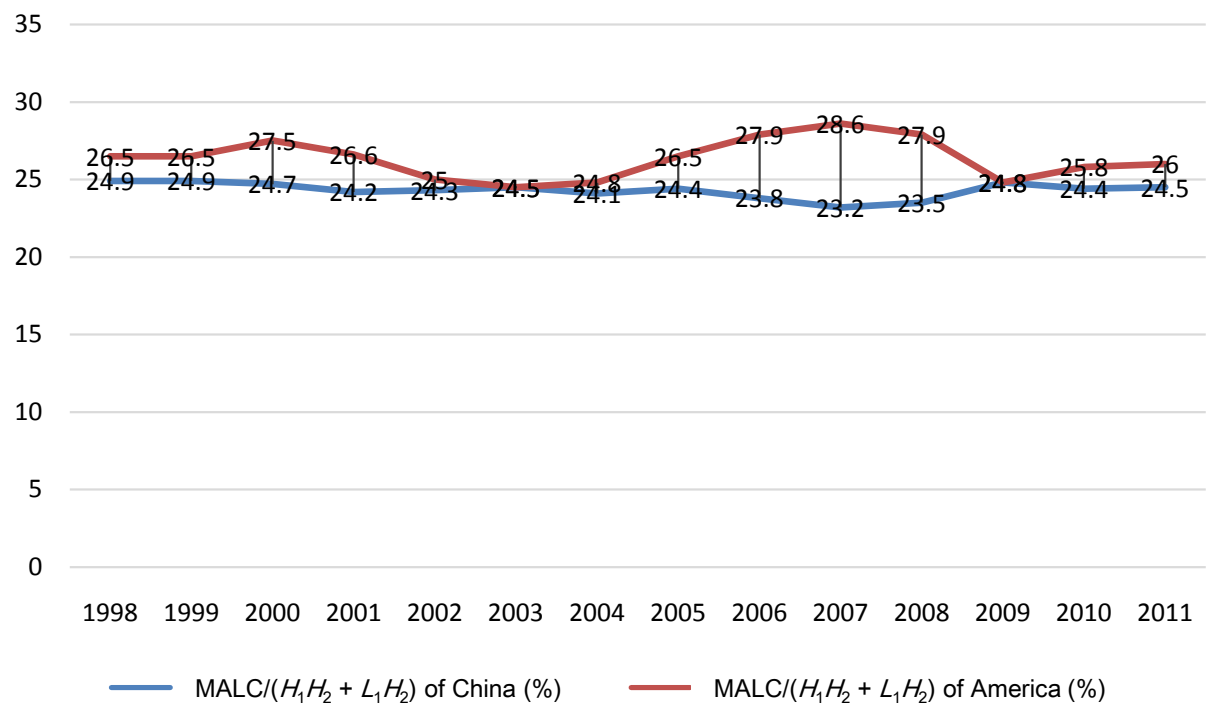

Figure 2. MALC of China and America (1998-2010) [2]-[5]. Caption: data in the figure shows the social logistics total cost proportion were significantly greater than the proportion of our country, it reached $37 \%$ in 2004 , although the financial crisis had shown the first signs in 2007, from its release of official data, it still had slow GDP growth in 2007-2008, it began to fall in 2009, but the decline is limited, it restore to \$14.5 trillion in 2010 (nominal GDP), Coupled with 2009, 2010, 2011, adjusted the social logistics total cost ratio reached $34.8 \%$, 36.7\% and $36.7 \%$ respectively in the three years. So we can reasonably speculated that social total cost of logistics in 2005-2008 will be decline slowly, but the degree is not enough to lower than the adjustment value of our country.

countries. If we formulate industry policy on this basis, it may eventually hinder the development of the owner enterprises and professional logistics entity.

After the above adjustment, just got rid of the industry without direct relations with the logistics activity, namely non material industry, the following we inspection the internal situation of physical production industry. In fact, there are two kinds of invisible factors affecting the logistics cost, one is the different added value produced by the different products, related to resources endowment and economic development level; the second is different locations in the industrial chain while produce the same product, it depends on whether having the core technology and the level of the core technology. 
Table 2. Contrast before and after the adjustment of America [3]-[5].

\begin{tabular}{ccc}
\hline Year & MALC/GDP of America (\%) & MALC/ $\left(H_{1} H_{2}+L_{1} H_{2}\right)$ of America (\%) \\
1998 & 10.1 & 26.5 \\
1999 & 9.9 & 26.5 \\
2000 & 10.2 & 26.5 \\
2001 & 9.5 & 25.0 \\
2002 & 8.7 & 24.5 \\
2003 & 8.5 & 24.8 \\
2004 & 8.7 & 26.5 \\
2005 & 9.3 & 27.9 \\
2006 & 9.8 & 28.6 \\
2007 & 9.9 & 27.9 \\
2008 & 9.4 & 24.8 \\
2009 & 7.9 & 25.8 \\
2010 & 8.3 & 26.0 \\
2011 & 8.5 & 2.9
\end{tabular}

Caption: source data in this table involved in the industry data was shown in the bureau of economic analysis of BEA website published industry data based on north American industry classification system, the final three industry data is separately calculated according to China's national bureau of statistics (NBS) set tube department issued "the provisions of the three divisions of industry", among them, transportation has no direct relations with logistics, but considering the comparability of data, added this item in accounting. In addition, the world bank WDI data in the database are provided for reference only, not directly involved in the calculation.

The first factor reflect to the model, we can divide the logistics cost into two parts, MALC $=C_{1}+C_{2}$, $C_{1}$ is logistics cost formed by the high value-added products, $C_{2}$ is logistics cost formed by the low value-added products. On the basis of this, Formula (3) can change into Formula (4):

$$
\operatorname{MALC} /\left(H_{1} H_{2}+L_{1} H_{2}\right)=\left(C_{1}+C_{2}\right) /\left(H_{1} H_{2}+L_{1} H_{2}\right)
$$

The denominator corresponds to $\mathrm{C}_{1}$ is $\mathrm{H}_{1} \mathrm{H}_{2}$, that is logistics cost formed by the high value-added products corresponding to the value of high added value product, the denominator corresponds to $\mathrm{C}_{2}$ is $\mathrm{L}_{1} \mathrm{H}_{2}$, that is logistics cost formed by the low value-added products corresponding to the value of low added value product. Normally, agriculture, forestry and fishing and low-end manufacturing industry generally belongs to the low value-added products, manufacturing industries with physical culture, brand and technology factors belong to high value-added manufacturing industries. Our country is in the transition stage of the developing countries, at this stage we still plays the role of the "world factory", low-end manufacturing, mining, steel and other rigid demand for logistics industry have large output, need to consume large amounts of logistics resources. And the United States are more inclined to the design of high precision instruments, high-end electronic products, etc. For our country, in the formula $\left(C_{1}+C_{2}\right) /\left(H_{1} H_{2}+L_{1} H_{2}\right)$, small output in the low value-added products consumed a large logistics resources, while relatively large output of high value-added products consumes less logistics resources, and the industrial products with high logistics demand coefficient create a larger share of total output (China's industrial logistics demand coefficient is high, it had been more than 2.0 since 2003), so the comprehensive situation will make the value of the Formula (4) on the high side, While the United States is just the opposite.

\section{Our social Logistics Cost Too Much?}

After this article second part of this paper, we realize that after the adjustment of the industrial structure and the output value of material production department, the actual data shows a completely opposite result: American MALC $/\left(H_{1} H_{2}+L_{1} H_{2}\right)$ is generally higher than the corresponding value of our country, but considering the statistical caliber, the antinomy between the benefit of logistics service quality, science and technology and economic development level, and many other factors, we can't directly come to the conclusion that our country lo- 
gistics comprehensive level is higher than the United States. But on empirical comparison, we have a good reason to break the misleading that social logistics cost of GDP is on the high side for a long time brought to us. At least won't simply think that social profits can be possibly increased by reducing the social logistics costs.

However, in examining the three components of macro logistics cost, we found that, the proportion of transportation cost to national material production output in China was $2.4 \%$ to $5.7 \%$ lower than the United States; Storage costs were $1 \%$ - $2 \%$ lower than the United States in addition to individual years, the logistics administrative expenses is significantly higher than the United States (Figure 3).

Due to the bridging between various mode of transportation of our country is poor, so as to make the multimodal transport development is relatively slow, the sea rail transport accounts for $2.6 \%$, while in America the proportion reached 40\%; Part of the coal transport channel rail capacity shortage, made the road share a number of long distance transportation, which increased transportation costs. In addition, low degree of transportation information and social resources organization also increased the transportation cost, according to the statistics, China's first 20 highway transportation enterprises accounted for the road market share is less than $2 \%$, only 1 of the individual transport households accounted for nearly $40 \%$ of the total road transport. In the United States, the largest 5 highway transport enterprises accounted for $60 \%$ of the road market share. In such a situation, the overall transport costs remain below the level of the United States, largely due to the low cost of human labor and lower transportation profit. China's warehouse area is only $25 \%$ of the United States, and there is no uniform standards and specifications for logistics equipment, so the cost cannot be reduced by using the general and the loop, In addition, most of the cities in China are in the growth stage, for government planning and other reasons, the warehouse location changes frequently and is far from the city center, most of them are storage type of warehouse, the change of location makes the cost of warehousing industry is huge, distribution to the center of the city also consumes a lot of transportation costs (Frequent transportation, Empty) and administrative expenses (cost of city, fine). The cost of logistics management deserves special attention, from Figure 3 it is clear to see that the cost of logistics management in the United States is between 0.9 - 1.1, the change is relatively stable, The corresponding ratio of our country in the 2.9 - 4.2, the change is more intense, and the proportion is high. Due to the "Business tax to value added tax" policy had not yet begun in 2011, therefore, the data does not reflect the change of "Business tax to value added tax", after the transportation industry implemented "Business tax to value added tax", tax rate rose to $11 \%$, but the time was short, the upgrading of logistics transportation facilities was not universal, so the deductible items was less, and the tax burden of the logistics enterprises in the goods transportation was not to reduce but to increase, which made the overall logistics management costs increase. In addition, highway toll, fines, etc. directly pushed up the overall logistics administrative costs. According to CCTV disclosed in 2011, logistics enterprises will bear the cost of nearly 700 billion Yuan in one year. $95 \%$ of the highway in our country is charge, and only $8.8 \%$ in the United States, the advantages and disadvantages of the toll of highway and the fine is not in the scope of this article, however, the arbitrary charges and fines caused by lax supervision has become a long-term obstacle to the development of transportation enterprises, which is also the reason of higher administrative costs overall logistics in our country.

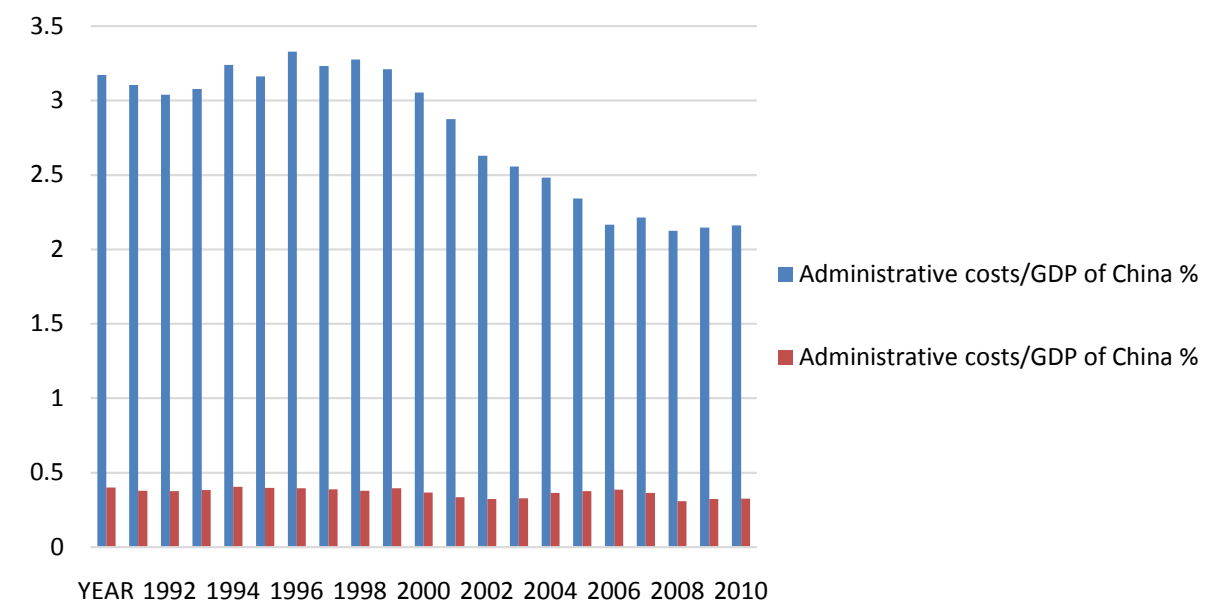

Figure 3. Administrative costs/GDP of China [2]-[5]. 


\section{Conclusions and What to Do Next?}

Based on the above analysis, it is relatively clear: the misunderstanding about the cost of logistics makes us think that the lower, the better. And we used to make some cheap and one-side conclusions by analyzing the single and simple ratio and the contrast to America and Japan and other developed countries have deteriorated this situation, which is not a scientific and comprehensive way to study the social phenomenon. The difference between China and developed countries, say, America and Japan, probably just shows a pure situation in special phase of our country's development process, no matter good or bad.

Besides that point of view, we do have some problems in logistics operations, and it is necessary to be solved urgently. For instance, the high logistics cost in the past time which has last for quite a long time, road tolls, the last kilometer distribution, empty driving and city policy which make warehouse site selection a burden and so on. In a word, we need to and we absolutely can improve the situation by optimizing the tax system and make the city policy more suitable for the development of logistics companies. The government can also promote the information technology in collaborative way, which can be very helpful.

\section{References}

[1] Li, K.N. (2002) On Logistics Cost and GNP. China Business and Market, No. 4, 11-13.

[2] China Statistical Yearbook and China Logistics Yearbook (Data Has Been Calculated and Rearranged).

[3] Logistics Costs and US Gross Domestic Product, Prepared for: Federal Highway Administration Department of Transportation, Prepared by: MacroSys Research and Technology, Washington DC, 25 August 2005.

[4] WDI Database from the World Bank.

[5] US Department of Commerce Bureau of Economic Analysis. 